\title{
TCOM \\ Science communication training as information seeking and processing: a theoretical approach to training early-career scientists
}

\section{Heather Akin, Shelly Rodgers and Jack C. Schultz}

Abstract

Keywords

DOI

Introduction
This study examines early-career scientists' cognition, affect, and behaviors before, during, and after a series of science communication training workshops drawing from the Risk Information Seeking and Processing (RISP) and Theory of Planned Behavior theoretical models. We find correlations between engagement (throughout the training), self-reported knowledge and intention to apply their science communication skills. We discuss implications of these findings for science communication training, in particular that science communication behaviors and investment in skill development appear to be more dependent on attitudes and motivations cultivated during the training, rather than their attitudes and motivations coming in.

Professionalism, professional development and training in science communication; Science communication: theory and models

https://doi.org/10.22323/2.20050206

Submitted: 16th October 2020

Accepted: 3rd July 2021

Published: 15th September 2021

The growing body of empirical work in the science of science communication supports the notion that scientists in any stage of their career can benefit from communicating their work with broader audiences [Cirino et al., 2017; Rodgers, Wang, Maras et al., 2018]. For scientists on the traditional tenure track, public communication of their research and its implications can support academic advancement [Jensen et al., 2008], be intrinsically rewarding [Dudo, 2013], assist in acquiring extramural funding [Byrnes et al., 2014], broaden the impact of their work [Besley, Dudo and Storksdieck, 2015; Liang et al., 2014], and help scientists engage in relevant public dialogue [Priest, 2013]. For students with PhDs in STEM disciplines who do not go on to tenure-track academic positions, estimated to be about 82 percent of recent STEM PhDs [National Academies of Sciences, Engineering, and Medicine, 2018], careers 'away from the bench' in policy, nonprofit, government, or media sectors are arguably more demanding of communication skills [AAAS, 2015]. This increasing need for STEM graduates to 
be competent in communicating their expertise to a diversity of audiences makes integrating science communication training into STEM higher education a valuable endeavor [Bankston and McDowell, 2018; National Academies of Sciences, Engineering, and Medicine, 2017].

Science communication skills not only benefit the scientist, but also help scientists engage with the public and contribute to broader societal goals. Scientists can serve as important intermediaries in the science-society landscape, as experts who may help dispel scientific myths and misinformation [Dudo, 2013; Dudo and Besley, 2016], clarify risks and benefits of scientific developments, and engage with audiences in a mutually constructive manner [Besley and Nisbet, 2013]. Further, as scientific advancements become more ethically complex, it is critical that scientists can explain their research and its societal implications to the lay public, policymakers, and other stakeholders [Akin et al., 2017; Scheufele, 2014]. These benefits to scientists and the public are underscored in a recent report by the U.S. National Academies of Science, Engineering, and Math, which stated that science communication skills should be deemed a 'core educational element' in STEM education, helping students "acquire the capacity to communicate, both orally and in written form, the significance and impact of a study or a body of work to all STEM professionals, other sectors that may utilize the results, and the public at large" [National Academies of Sciences, Engineering, and Medicine, 2018, p. 106].

Importantly, science communication training strategies are cautioned to avoid perpetuating the 'deficit model' of communication, which is characterized by a one-way dissemination of information from experts to public audiences and other stakeholders [Besley, Dudo and Storksdieck, 2015; Copple et al., 2020]. Instead, research supports that scientists be deliberate and responsible with their public communication and engagement, which could also be mutually beneficial in that it helps scientists gain a broader understanding of the societal implications and public perceptions of their work [Besley and Tanner, 2011; Copple et al., 2020].

While this study does not aim to critique the approaches of existing science communication training, it does seek to better understand the perceptions and intentions of early-career scientists - and graduate students in particular participating in science communication training. To do this, we draw from research in science communication and science education to purpose a theoretical approach to understanding early-career scientists' cognition, affect, and behavioral intentions before, during, and after science communication training workshops. The model is based on theories commonly used in science communication research and science education research — including the Theory of Planned Behavior and the Risk Information Seeking and Processing Model — which, to date, have not been tested in the context of students undergoing a communication training program. We test the efficacy of our model using data from a series of science communication workshops conducted with 59 STEM graduate students at the University of Missouri in the United States. Our findings acknowledge the influence of perceived norms of communicating science, the worry or negative affect involved in obtaining these skills, preparation throughout the workshops, perceptions of behavioral control in utilizing these skills, assessments of being informed, and how, following the training, trainees reflect on and expect to use their gained knowledge. 
Theoretical

framework:

determining

science

communication

'action'
How do early-career scientists perceive of and intend to use communication skills gained through a formal training process? Surprisingly, few studies to date have conducted research on the underlying attitudes, perceptions, and intentions of participants in science communication training. Although numerous institutions and programs have developed and implemented science communication training in the higher education context and beyond [e.g., Besley, O'Hara and Dudo, 2019; Clark et al., 2016; Illman, 2010; Neeley et al., 2014; O'Keeffe and Bain, 2018; Ritchie and McCartney, 2019; Warren et al., 2007], which provide insightful evaluations and summaries, few have analyzed the perspectives of participants going through science communication training within a theoretical framework that would help to explain perceptions more generally. Doing so would also help incorporate the viewpoints of students and early-career scientists into a broader understanding of science communication skill development, which has tended to focus on perspectives of more experienced scientists [Matthews and Mercer-Mapstone, 2018].

The perspective of graduate students participating in skill development underscores the reality that the fields of science education and science communication research are often seen as distinct bodies of work [Baram-Tsabari and Osborne, 2015]. Yet, studying participants' views about science communication training in higher education provides an opportunity for researchers to weave together complementary models used in each field [McKinnon and Vos, 2015]. By studying the perceptions of students and aspiring scientists participating in science communication training, the individuals being studied are both learners and science-communicators-in-training. From the students' or trainees' perspectives, participating in science communication training is both a decision to engage in professional development and an activity that could correlate with the intended (or planned) behavior of applying learned communication skills in the future. It is also notable that the stage of one's career or amount of professional experience may affect views toward science communication and science engagement activities. For instance, Besley, Dudo and Yuan [2018] find that younger scientists may be more interested in online engagement activities but less interested in communicating via traditional news outlets.

A vast amount of research in communication, education, psychology, and other social science fields investigate what beliefs, attitudes, and motivations drive individuals to avoid or engage in specific behaviors. This work has been widely applied in both science education and science communication contexts. For science education in higher education, research has explored how students' perceptions of their autonomy, intrinsic motivations, and extrinsic motivations impact student learning, achievement, retention, and professional development [Jeno, 2015; Jeno, Danielsen and Raaheim, 2018; Rizzolo et al., 2016]. In the context of science communication research, much of this work has been conducted in relation to individuals' views toward personal or societal risks, such as perceptions of emerging technologies or policy preferences related to science topics [Akin et al., 2020], adopting pro-health behaviors [Lundborg and Andersson, 2008], or taking actions to prevent environmental harm [Flynn, Slovic and Mertz, 1994]. We argue that these approaches are highly relevant to the context of science communication training as well. While receiving training in science communication may not seem like risk aversion per se, it can be considered an information-seeking behavior [Griffin, Dunwoody and Yang, 2013]: science communication trainees invest the 
time and effort required to feel as though they have the skills needed to communicate effectively. Altogether, research in both science education and science communication acknowledge that behaviors and intended behaviors are strongly correlated with personal cognition, affect, motivations, and perceptions of their own capabilities [Ajzen, 1991; Besley, O'Hara and Dudo, 2019; Montaño and Kasprzyk, 2015; Rizzolo et al., 2016].

As noted, cognitive, affective, and motivational factors correlate with individuals engaging in specific behaviors, as proposed by the Theory of Planned Behavior [Ajzen, 1991] and the Integrated Behavioral Model [Copple et al., 2020] (for more detail on the historical development of these models, readers are referred to Montaño and Kasprzyk [2015]). Altogether these models offer support that attitude, affect, perceived norms, and personal agency (i.e., efficacy) are significant determinants in the intention to perform a given behavior, as long as relevant and applicable measures of behaviors are used [Montaño and Kasprzyk, 2015]. Put briefly, these models support the notion that intentions to adopt a behavior (behavioral intentions) are influenced by beliefs about the social expectations to behave in that way (subjective norms), the attitude toward that behavior (e.g., perceptions of the advantages and emotions or affect toward it), and how capable one deems oneself of performing the behavior (perceived behavioral control or self-efficacy) [Ajzen, 1991; Griffin, Dunwoody and Yang, 2013, pp. 328-329]. In the field of risk communication, these models that aim to predict behaviors and behavioral intentions have been updated to account for the variable of information processing. For instance, research applying the Risk Information Seeking and Processing (RISP) model [Dunwoody and Griffin, 2015; Griffin, Yang et al., 2008; Griffin, Dunwoody and Yang, 2013] finds that individuals' affect, sense of efficacy, and normative perceptions are linked to information seeking and processing behavior. In other words, information seeking is a behavioral outcome individuals, seeking a sense of information sufficiency, will put in the effort or practice required to achieve their goals [Eagly and Chaiken, 1993; Griffin, Dunwoody and Yang, 2013].

While behavioral models have been applied to test how scientists perceive of science communication activities and training [Besley, O'Hara and Dudo, 2019; Copple et al., 2020; Poliakoff and Webb, 2007], most have used cross-sectional surveys of scientists to examine these relationships. In the study presented here, we test the relationships between key variables in the Theory of Planned Behavior and Risk Information Seeking and Processing model among STEM graduate students as they participate in science communication training. From the perspective of a scientist or aspiring scientist, one of the characteristics associated with willingness to seek out science communication training may be the belief that they have the capacity to apply the skills when needed and to achieve their goals, which we conceptualize as science communication self-efficacy. We hypothesize that:

\section{H1: Individuals' science communication self-efficacy (pre-workshop) is positively related to presentation preparation throughout the workshops.}

Affect (such as worry or fear) may also impact individuals' motivations and cognitions related to participating in science communication training. Affective responses are considered important in the process of risk information seeking and 
processing, and are increasingly found to be significant indicators in behavioral models like TPB (for more discussion on this topic, see Manstead [2011]). It is noteworthy that affect can evoke different behavioral responses - worry, fear, or anxiety can motivate behaviors or deter them. Research to date does not suggest a directional hypothesis in terms of how negative affect will influence behaviors in science communication training workshops, and so we pose the following as a research question:

\section{RQ1: How is negative affect/anxiety preceding workshop participation related to presentation preparation throughout the workshops?}

Further, social norms are found to be influential across a range of behavioral and information seeking contexts. We argue this is particularly applicable to the context of science communication training for aspiring scientists. Specifically, graduate students' perceptions of their mentors' and peers' expectations of them, as well as the culture of their academic discipline, may affect how willing they are to invest time and effort into a new training that could benefit their career. While in some scientific disciplines public communication and outreach are discouraged and are not considered a valuable use of a scientist's time [Jensen et al., 2008], a perception that the training is valuable would likely correlate with effort put into the workshops. In light of this, we propose that:

\section{H2: Perceived informational norms are positively related to presentation preparation throughout the workshops.}

In addition to examining how participants' motivations, affect, and perceptions of norms may affect the effort they put into preparing for the workshops, we also consider how, upon completing the training, workshop participants' will rate their level of knowledge of science communication strategies. Specifically, we propose that:

H3: Presentation preparation throughout the workshops is positively related to (self-reported) science communication knowledge following the training.

We next examine whether the pre-existing motivations, affect, and social norms contribute to this self-reported knowledge. Because participants are likely to come into such a training with perceptions of their own capacity to learn skills and succeed in the training, we hypothesize that this is correlated with their self-assessed science communication knowledge upon completing the training. In addition, it is possible that this sense of self-efficacy could also be engrained and cultivated throughout the workshops. We hypothesize that:

H4: A motivation of science communication self-efficacy (a) before and (b) after the workshops is positively related to (self-reported) science communication knowledge following the training. 
Similarly, we theorize that affect and anxiety might also motivate behaviors related to the workshops, but we are unsure how it might affect behavioral response in this context, and therefore pose the following research question:

RQ2: How is negative affect/anxiety preceding workshop participation related to (self-reported) science communication knowledge following the training?

As proposed by the behavior models described above, belief that others, such as academic advisors and peers, consider science communication training as valuable (perceptions of norms) will also translate to participants' perception that they have gained knowledge and skills from the training. We hypothesize:

H5: Perceived informational norms are positively related to (self-reported) science communication knowledge following the training.

In the context of science communication training, we consider whether the motivations, attitudes, affect, and self-reported science knowledge (after participating in the workshops) are also related to the intention to apply learned skills in future settings. Specifically, we hypothesize:

H6: A motivation of science communication self-efficacy (a) before and (b) after the workshops is positively related to behavioral intentions to use learned science communication skills.

H7: Perceived informational norms are positively related to behavioral intentions to use learned science communication skills.

H8: Self-reported science communication knowledge is positively related to behavioral intentions to use learned science communication skills.

H9: Presentation preparation throughout the workshops is positively related to behavioral intentions to use learned science communication skills.

The program studied was an iterative and experiential science communication training with four cohorts of STEM graduate students at a large university in the Midwestern United States. Each set of workshops was designed to provide hands-on training beginning with a foundation of general communication skills and concepts and progressing to more specific communication skills and concepts in subsequent sessions. Each session was designed to include a workshop followed by a rehearsal to incorporate theoretical background along with practical skills-training followed by experiential learning and practice. The project aimed to draw students from a diversity of STEM disciplines and students were recruited to participate via departmental graduate student listservs, flyers, and word-of-mouth through students and faculty members. The study was approved by the University of Missouri's Institutional Review Board (IRB), and informed consent was obtained by participants at the beginning of the workshops. 
The sessions were led by faculty trainers who included examples from STEM fields to make the content and principles relevant to students. This content retained the principles and practice of effective science communication delivery, accompanied by content that suited the needs and interests of the specific trainees (for a thorough description see Rodgers, Wang, Maras et al. [2018]). There were, on average, 15 participants in each set of workshops, yielding a total sample size of 59 . Figure 1 depicts the timeline of when measures described below were asked of participants (i.e., before, during, or after the workshops). Development and preliminary validation of the scales is described and reported in a scholarly journal [Rodgers, Wang and Schultz, 2020].
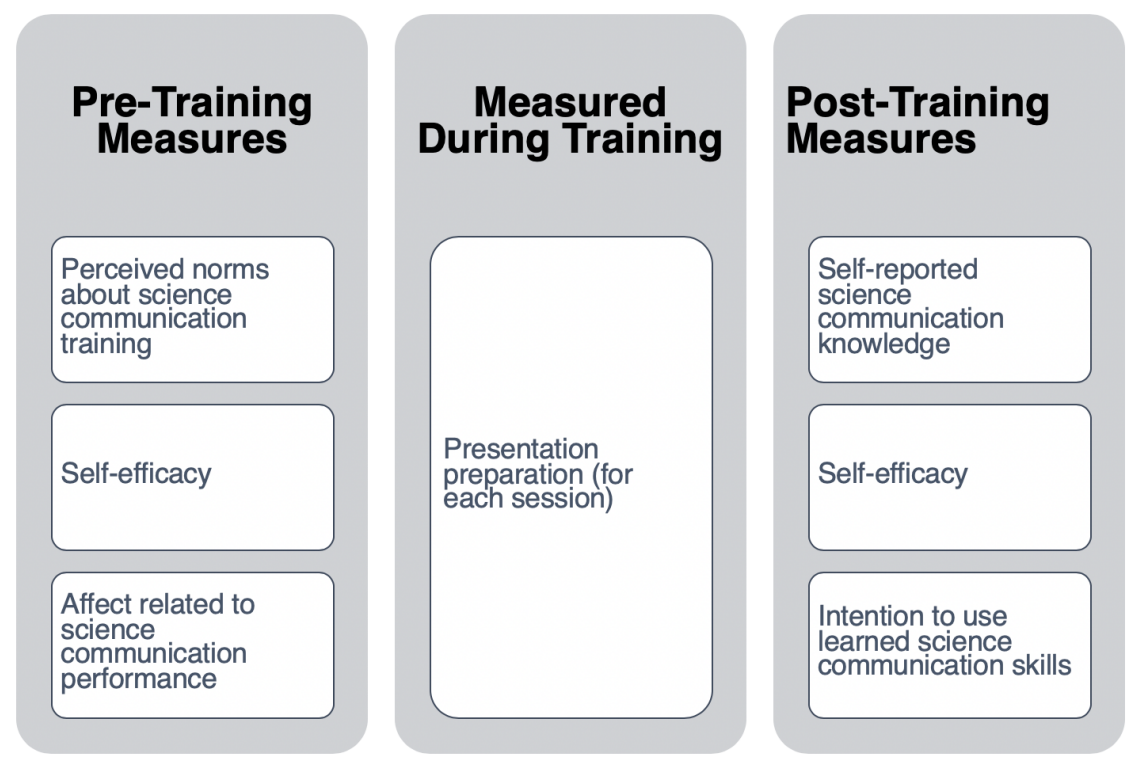

Figure 1. Timeline of data gathered from participants before, during, and after the series of science communication training workshops.

\section{Independent measures}

Self-efficacy. Participants' self-reported science communication self-efficacy was recorded using five items measured on a scale from 1 to 4 with scale points of 1-'Not at all true', 2-'Hardly true, 3-'Moderately true' and 4-'Exactly true' [Anderson et al., 2016; Schwarzer and Jerusalem, 1995]. Each set of items was asked both before participating in the workshops and after the workshops concluded and included statements such as 'I can always manage to solve difficult problems in science communication if I try hard enough" and "I can remain calm when facing science communication difficulties because I can rely on my coping abilities". The five items showed internal consistency when asked both before (Cronbach's $\alpha=.77$ ) and after the workshops (Cronbach's $\alpha=.80$ ), and were averaged together to form two scales: pre-workshop science communication self-efficacy and post-workshop science communication self-efficacy.

Affect. Participants' negative affect or worry about their ability to perform or succeed was assessed using two items measured on a 5-point Likert scale ranging from 1 ('Strongly disagree') to 5 ('Strongly agree'). These items were "I am worried about my ability to succeed in the science communication workshops" and "I am 
stressed out thinking I may fail the science communication workshops". The two items were significantly correlated (Pearson's $r=.69, p<.001$ ) and averaged to form an index of affect related to the science communication workshops.

Perceived social norms. In this study, we conceptualize social norms to be how STEM graduate students perceive important and respected others (e.g., advisors, peers) view and valuing the ability to translate science findings to a lay audience. Informational/injunctive subjective norms were measured with three items on 5-point Likert scales from 1-'Strongly disagree' to 5-'Strong agree'. The three items included "Most people who are important to me think I should stay on top of information about science communication" and "My advisor and/or my peers think I should get science communication training", and "My peers think I should get science communication training". The items demonstrated an acceptable level of internal consistency (Cronbach's $\alpha=.69$ ) and were averaged to form an index of social norms.

\section{Dependent measures}

Presentation preparation (self-reported behavior). The self-reported behavior of presentation preparation was measured using a set of six items, and each set was asked after each of the four sessions that made up the training. The six items asked participants to indicate on a 5-point scale (ranging from 1-'Strongly disagree' to 5-'Strongly agree') how much they agreed with the statements: "I relied on multiple kinds of information when I created my presentation"; "I drew on the principles I learned in the workshop to create my presentation"; "I put a lot of time into creating my presentation"; "I put a lot of effort into creating my presentation"; "I wasn't sure how to translate the workshop ideas into my presentation" (reverse-coded); and "I'm unsure if I accomplished the goals of the workshop in my presentation" (reverse-coded). Each set of six items was averaged into its own scale for each session and these indices were then averaged together, resulting in four indices. Those subsequent four indices (one index for each session of the training) had an acceptable level of internal consistency with one another (Cronbach's $\alpha=.62$ ) and were averaged together to create the final variable of presentation preparation.

Science communication knowledge (as information seeking). Participants' self-reported science communication knowledge was measured with one item that was asked after their participation in the workshops. The question was "How much do you currently know about science communication?" with participants answering on a scale from 0 ("I know nothing at all about science communication") to 100 ("I know all I could possibly know about science communication").

Using learned skills (behavioral intention). The post-training measure of behavioral intention to use learned skills consisted of three items measured on 7-point scales ranging from 1-'Not very likely' to 7-'Highly likely'. Statements included: "How likely are you to use the science communication skills the next time you make a speech?"; "How likely are you to use the science communication skills the next conference you attend?"; and, finally, "How likely are you to use the science communication skills once on the job?". Combined, the three items showed 
internal consistency (Cronbach's $\alpha=.80$ ) and were averaged to form the index likelihood of using learned skills.

\section{Analysis}

Before conducting the main analyses, analysis of variance tests explored whether there were differences in the main outcome variables between the four cohorts. The ANOVAs revealed significant differences in only two variables: workshop preparation, $F(3,55)=2.89, p=.04$, and intention to use learned skills $F(3,52)=3.03, p=.04$. We view this as a positive indication that the workshops were applied in essentially consistent ways and the two detected significant relationships were likely due to individual differences that occur with convenience sampling. We argue this justifies combining the four cohorts of data but pay attention to the two items that yielded significant differences. Bivariate correlations (Pearson's $r$ ) were used to examine our hypothesized relationships.

\section{Results}

The results we report examine the application of the behavioral models including the Theory of Planned Behavior and Risk Information-Seeking and Processing (RISP) and its relevance in the context of a series of science communication workshops for STEM graduate students. We test whether students' attitudes and motivations coming into the training - in terms of their perceptions of self-efficacy, perceptions of injunctive norms, and worry and fear - impact what they put into the training as presentation preparation. We also examine how these characteristics influence STEM graduate students' beliefs about their own science communication knowledge after the conclusion of the training, as well as their behavioral intention to use learned skills in the future. Table 1 provides a summary of the variables and scales used in the analysis. Figure 2 depicts the results of our analysis.

Table 1. Summary of variables and scales used in analysis of participants' perceptions of science communication training.

\begin{tabular}{|l|cc|}
\hline & Mean & Std. dev. \\
\hline Independent variables & & \\
Pre-workshop science communication self-efficacy (5 items) -1-4 & 3.04 & 0.47 \\
Post-workshop science communication self-efficacy (5 items) - 1-4 & 3.50 & 0.41 \\
Negative affect (2 items) - 1-5 & 2.36 & 0.88 \\
Normative perceptions (3 items) - 1-5 & 3.16 & 0.77 \\
Dependent variables & & \\
Workshop preparation (6 items for each of 4 workshops) - 1-5 & 3.71 & 0.39 \\
Self-reported science communication knowledge (1 item) - - -100 & 79.88 & 10.71 \\
Intention to use learned skills (3 items) - 1-7 & 6.58 & 0.63 \\
\hline
\end{tabular}

Note: see main text for measurement of specific items. Number of items in each index in parentheses, followed by the range of the scaled used.

Our first set of hypotheses and research question address the influence of participants' preexisting mindset as they came into the training. Our first hypothesis (H1) examined whether self-efficacy measured before beginning the workshops was correlated with preparation for oral presentations throughout the workshops, and was not supported $(r=.09, p=.25)$. Because the RISP and other 


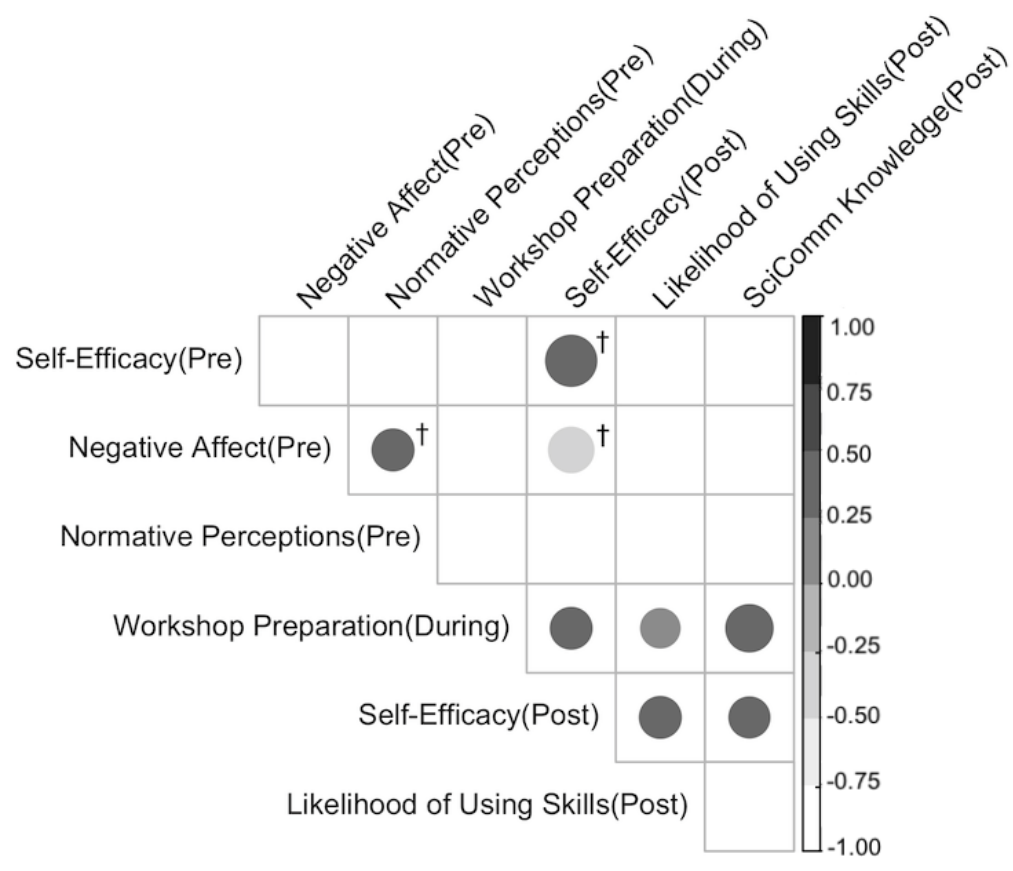

Figure 2. Correlogram depicting significant correlations (Pearson's $r$ ) between variables measured before, during, and after STEM graduate students' participation in science communication training program. Darker shades denote positive correlations and lighter shades denote negative correlations. The shade and size of the circles are proportional to the correlation coefficients. Correlations notated with $t$ are significant but were not set forth as hypotheses. $N=59$.

relevant models did not show consistent results for the role of emotion or affect, we posed as a research question whether negative affect was correlated with preparation for presentations throughout the workshops. This showed no significant relationship $(r=-.10, p=.22)$. Moving on, we found that for reported informational norms - operationalized as the view that important others believe they should participate and be trained in science communication - was not significantly correlated with level of preparation for the workshops $(r=.12$, $p=.19)$, and so $\mathrm{H} 2$ was not supported.

Our next set of hypotheses examined how the behavior of preparation and attitudinal and motivational factors affect outcomes in terms of STEM graduate students' perceptions about their science communication knowledge. The hypothesis (H3) revealed that time and effort put into preparing for the workshops throughout the training was significantly and positively correlated with reported science communication knowledge $(r=.34, p=.006)$. The next hypothesis, which considered whether participants' sense of science communication self-efficacy both before ( $\mathrm{H} 4 \mathrm{a})$ and after $(\mathrm{H} 4 \mathrm{~b})$ the workshops was related to participants' reported science communication knowledge, was partially supported. We found pre-workshop self-efficacy was not significantly related to participants' reported science communication knowledge $(r=.12, p=.20)$, but post-workshop self-efficacy was correlated with science communication knowledge $(r=.25$, $p=.03)$. Notably, though it was not presented as a formal hypothesis, a post-hoc test demonstrated there was a significant increase in self-efficacy ratings $t(55)=6.68, p<.001$ when comparing STEM graduate students' pre- to post-workshop ratings. 
In terms of the next research question (RQ2), our analysis shows there is no statistically significant relationship between negative affect/anxiety related to science communication efforts and perceived science communication knowledge after the workshops $(r=-.20, p=.14)$. Nor was there a statistically significant relationship (H5) between science communication-related social norms and reported science communication knowledge after participating in the workshops $(r=.11, p=.22)$.

Our final set of analyses examined how pre-workshop attitudes and motivations, as well as preparation and perceptions fostered throughout the workshops, impact a behavioral intention to use the skills learned from participating in the science communication training. In the first of these we examined the impact of self-efficacy reports both before $(\mathrm{H} 6 \mathrm{a})$ and after $(\mathrm{H} 6 \mathrm{~b})$ participating in the training, which was partially supported. Pre-workshop reported self-efficacy related to science communication was not significantly correlated with the behavioral intention to use learned science communication skills $(r=.15, p=.27)$, but post-workshop self-efficacy was significantly correlated with the intention to use learned science communication skills $(r=.26, p=.05)$.

Our research question that examined the role of negative affect in potentially influencing the behavioral intention to use learned skills (RQ3) did not show a significant relationship $(r=-.04, p=.39)$. Additionally, reported informational norms or others' perceived expectations to gain science communication skills (H7) was not related to STEM graduate students' reported intention to use science communication skills $(r=-.13, p=.17)$. The next hypothesis (H8) considered whether reported science communication knowledge and intention to use learned science communication skills was not significant at the established $p<.05$ level $(r=.19, p=.08)$, but the results indicate a trend toward greater reported science communication knowledge correlating positively with student participants' intention to use skills learned from the workshops. Our final hypothesis (H9), which tested for a relationship between preparing for presentations throughout the course of the workshops and intention to use learned skills was supported $(r=.23$, $p=.04)$.

\section{Discussion}

The intent of this study was to examine the applicability of a theoretical cognitive-affective-behavioral model in the context of science communication training conducted with STEM graduate students. Specifically, we sought to examine whether elements of the Theory of Planned Behavior (TPB) [Ajzen, 1991] and Risk Information Seeking and Processing (RISP) model [Dunwoody and Griffin, 2015; Griffin, Dunwoody and Yang, 2013] conceptually and operationally apply to the context of a training in science communication skills for early-career scientists. The science communication training program was taught by faculty trainers to four cohorts of STEM graduate students, with a total of 59 participants in the series of four workshops of the science communication training. We examined whether participants' mindset coming into the program, including their negative affect/worry about participating, perceptions of social norms or expectations of important others to gain such training or skills, and motivational aspects including perceptions of science communication self-efficacy affected their opinions about their own science communication knowledge (post-workshop), involvement in the workshops via preparation for each presentation, and 
behavioral intentions to use learned science communication skills. While our study included a relatively small sample of 59 participants, our results lend support for a theoretical model that predicts information seeking and subsequent behavior. The data reveal relationships that have both theoretical and practical implications for science communication training and other graduate-level professional development activities, as well as insights into how individuals process skill development and risk-related information in a new context. We advise that readers bear in mind the characteristics of this study — including the sample size, the fact that the training occurred at one university, and participants' career stage - when considering the generalizability of the findings. Here we discuss the implications of each of our findings in turn.

The first set of hypotheses and research question $(\mathrm{H} 1, \mathrm{RQ} 1, \mathrm{H} 2)$ evaluates the impact of participants' perspectives and beliefs about their science communication skills, as well as their perceptions about pre-training culture in the STEM disciplines, on how much they put into the training (i.e., an aggregated measure of how much they prepared for the sessions across the course of the workshop). Interestingly, our analysis did not reveal significant relationships - participants' mindset before the training, in terms of their efficacy to be effective science communicators, their fear and worry about their performance in the workshops, and their beliefs about what others expect of them were not significantly correlated with how much preparation time and effort they invested throughout the training. The lack of significant relationships here could be valuable information for engaging scientists-in-training to gain science communication skills. Specifically, our data suggest that pre-existing norms and attitudes may not determine how much trainees invest in this form of professional development - whether aspiring scientists are very confident (efficacious) in their ability to succeed or not confident at all, or whether their colleagues and mentors are very supportive or indifferent, will not dictate their level of investment. In short, differences in levels of self-efficacy, worry, or different perceptions of the culture or expectations within their discipline, does not dictate the time and effort given during the training, although these have been found to be significant predictors of information seeking behavior in prior research [Griffin, Dunwoody and Yang, 2013]. It is possible that because the trainees in this program were a self-selected group of volunteers, they were uniquely motivated to gain public communication skills and may not reflect the breadth of feelings among their peers.

Our next set of hypotheses (H3-H5) and research question (RQ2) considered how cognitive and affective characteristics were then correlated with a post-workshop measure of self-reported science communication knowledge. This hypothesis tested elements of the Theory of Planned Behavior [Ajzen, 1991] and Risk Information Seeking and Processing model [Griffin, Dunwoody and Yang, 2013]: whether negative affect, normative beliefs, and self-efficacy (pre- and post-workshop) were associated with a perception of knowledge, which could also be described as information sufficiency. Our third hypothesis utilized the just-described variable of presentation preparation throughout the workshops, now tested as an independent variable. Our data show that presentation preparation throughout the training was positively associated with reported science communication knowledge following completion of the workshop. This makes intuitive sense, given that educational research would suggest that time, effort, and repetition will result in better learning outcomes and greater 
self-reported knowledge, as well as confidence in that knowledge. But this finding also demonstrates how components of the TPB and RISP models might function in new contexts: that information seeking and processing (via practicing and preparing throughout the training) will also contribute to a perception of information sufficiency.

The next hypothesis then, $\mathrm{H} 4$, looked at how trainees' sense of self-efficacy both before and after the workshops correlated with science communication knowledge. While pre-workshop self-efficacy ratings were not associated with trainees' reported knowledge post-training, post-workshop self-efficacy ratings were positively correlated with science communication knowledge. As alluded to with our findings from the relationship between pre-workshop self-efficacy and presentation preparation (H1), the lack of statistical significance is also an informative result given that it suggests even individuals with low science communication self-efficacy can still gain from the training and feel they are knowledgeable. At the same time, the finding that post-workshop self-efficacy correlated with resulting science communication knowledge also has implications for those interested in promoting confidence and knowledge among early-career scientists. In relation to the theory, it is notable that self-efficacy or perceived behavioral control has been found to be a robust indicator of knowledge or information sufficiency [Ajzen, 1991; Griffin, Dunwoody and Yang, 2013], yet in our study only post-training self-efficacy was statistically significant. From a practical standpoint, training could include elements and activities that foster perceptions of self-efficacy, which our data also show is related to science communication knowledge (though we cannot claim causation here given that post-workshop self-efficacy and science communication knowledge were measured at the same time point).

The next research question (RQ2) and hypothesis (H5) also tested the outcome of science knowledge. The results of our second research question found that negative affect (worry or anxiety) and science communication knowledge following the training were not significantly correlated, which has been the case in other studies that apply the RISP model [see Griffin, Dunwoody and Yang, 2013]. The correlation between normative perceptions related to science communication (measured before the workshop) and science communication was also not statistically significant, although prior research suggests that in the RISP it is a predictor of information sufficiency [Griffin, Yang et al., 2008]. Again, statistical insignificance provides valuable insights, especially because they compare attitudes and cognition measured before participating in the series of workshops.

Our next (last) set of hypotheses (H6-H8) and research question (RQ3) looked at the impact of affect, cognition, and reported science knowledge on the behavioral intention to use the skills learned throughout the course of the workshop. Our sixth hypothesis revealed that pre-workshop self-efficacy was not significantly correlated with the likelihood of using learned skills, though post-workshop self-efficacy was significantly correlated with likelihood of using learned skills, as theorized by the Theory of Planned Behavior [Ajzen, 1991]. This is consistent with our results from the hypothesis testing the dependent variable of science communication knowledge, but this case applies to an intended behavior to apply the skills and competencies acquired during the workshops. Again, the mindset coming into the workshops appears to be less influential than what happens during the workshop, 
which suggests that the process of training and rehearsing in a collaborative environment may cultivate self-efficacy and also help trainees to understand the relevance and their capability of using science communication strategies. Also, like the hypothesis examining the impact of science communication knowledge, the independent variables (measured before trainees took the science communication training) of negative affect (RQ3) and normative perceptions about what important others and peers expect of them (H7), did not influence their intention to use the skills acquired during the training. Finally, our data revealed that science communication knowledge and the intention to use the skills (H8) gained were significantly correlated with one another. Because these two variables were recorded after trainees completed the workshop, they reveal an important and constructive outcome of participating in the program: higher self-reported science knowledge is associated with a greater intention to use the skills they have gained. If trainees are encouraged and given practical tips to employ the science communication skills they have learned, they may also feel more knowledgeable about the value of and effective modes of science communication overall (though we, again, cannot claim a causal direction, it demonstrates that encouraging beliefs or intentions during the training can yield positive results).

\section{Limitations}

It is important to note that the size of our dataset and characteristics of our sample limited the statistical analysis that could be used. This small sample size of 59 participants limited our statistical power and the statistical tests that could be used. Additionally, the sample was a small and self-selected group that may have already come in with (for example) greater confidence, self-efficacy, or knowledge. This may have minimized the impact we observed on variables such as the culture in STEM fields (i.e., normative perceptions, affect, etc.). It may be that with a larger and more diverse sample, we would observe stronger relationships between some of our variables. Nevertheless, our use of bivariate correlations revealed some interesting relationships that provide insight into science communication trainees' motivations, attitudes, and behaviors before, during, and after the workshops. Given our small sample size, it is possible that with a larger sample size we would see even stronger relationships, so further research or a replication of the current study is warranted. Another acknowledgement is that our participants were panelists who responded to the surveys at multiple time points throughout the training, which allows us to consider some of our results causal in nature (for example, the relationship between presentation preparation and likelihood of using learned science communication skills). However, some of our hypotheses tested variables were measured cross-sectionally, and so we can only acknowledge correlation (e.g., the relationship between post-workshop science communication self-efficacy and likelihood of using learned skills). And lastly, although most of our measures used multiple items that showed internal consistency, one of our dependent variables — self-reported science knowledge — was a single-item indicator. cognition, affect, and behaviors (and behavioral intentions) of early-career STEM graduate students participating in science communication training. Though we 
acknowledge that our study analyzes a relatively small sample of students in one training program, we assert there are insights that can be gleaned from the significant relationships between variables captured after (or during) STEM graduate students' participation in the training. Several variables including pre-workshop motivations, perceived social norms, and negative affect or worry were not correlated with reported science communication knowledge or behaviors (preparation during the workshops) or the behavioral intention to use learned science communication skills following the training. This is somewhat surprising, given that it is to be expected that one's mindset coming into a program would factor into the effort they put into it or what they get out of it.

However, this has practical implications for science communication trainers, academic advisors, and others who seek to foster science communication skills. It is useful to know that several of the pre-workshop attitudes and motivations (those that might be outside the control of those organizing and leading science communication workshops) are not significantly related to the (arguably) most impactful outcomes of such a training: resulting knowledge and behavioral intentions. If these were deemed significant predictors of success in science communication, it might be difficult to change, for example, individuals' self-efficacy before participating in order to promote intentions to use science communication skills or report that they believe they know a lot. On the other hand, the significant relationships in our data illustrate there are characteristics that could be cultivated during science communication training — specifically individuals' science communication self-efficacy. In our analysis, pre-workshop self-efficacy was not significantly related to time and effort put into preparing during the workshops, perceived science knowledge after the training, or participants' stated likelihood of using learned science communication skills in future contexts. But science communication self-efficacy reported after the workshops was related to trainees' reported level of science knowledge and their intention to use the science communication skills they gained. These results suggest that self-efficacy is both an outcome and state of mind that may have ancillary benefits. In short, science communication workshops could incorporate strategies that foster a sense of self-efficacy in conjunction with the obvious skills of communicating science to the public. It might also be worthwhile to build this into graduate training and professional development for graduate students and other early career scientists.

Our findings also have implications for understanding planned behavior and risk information seeking in the context of science communication training.

As described by Griffin, Dunwoody and Yang, "Information processing is the keystone of the RISP model, and forms the primary theoretical gateway between communication-related variables and their potential impacts on the structure and stability of risk-related beliefs, attitudes, and behavior" [2013, p. 334]. In this study, we apply the information processing component to science communication training and examine what attitudes, beliefs, and affect contribute to information processing and test the impact of the training on reported knowledge, perceptions of efficacy, and behavioral intentions (to use skills gained). Interestingly, we find that the mindset coming into the training (the setting for information processing) such as worry or fear, social norms, and self-efficacy do not play a role in effort put into the training, although participation does correlate with trainees' mindset when they complete the training, as well as their self-efficacy and intention to apply the 
skills they have gained. Given that these key variables denoted in the TPB and RISP were not significant factors in our analysis, it suggests that when applied to science communication training they are not determinants of information seeking and processing in this context.

Bearing in mind these positive outcomes but also potential limits to scientists engaging in public communication of science, training students in science communication is an important opportunity with potentially great rewards for multiple stakeholders. Where formal science communication training does exist, it is important that they be empirically measured to test for what types of programs are most effective and what attitudes and intentions the participants have in terms of how they will use their skills (upon completion). Ideally, the personal characteristics and scientists' inherent attitudes and motivations could also be rooted in a theoretical framework that has shown to hold across comparable situations. Future research could contribute to a better understanding of these relationships by capturing data from participants in other training. Researchers might also consider refining measures, such as self-reported knowledge and positive affect (e.g., enjoyment in science communication activities).

Funding

Funding is provided by a National Science Foundation Grant \#1545177, "NRT-IGE: A Test Bed for STEM Graduate Student Communication Training".

References

AAAS (2015). Career trends: careers away from the bench. Advice and options for scientists. Science Careers. Washington, DC, U.S.A. URL: https ://www . science mag.org/booklets/career-trends-careers-away-bench.

Ajzen, I. (1991). 'The theory of planned behavior'. Organizational Behavior and Human Decision Processes 50 (2), pp. 179-211. https://doi.org/10.1016/0749-5978(91)90020-T.

Akin, H., Cacciatore, M. A., Yeo, S. K., Brossard, D., Scheufele, D. A. and Xenos, M. A. (2020). 'Publics' support for novel and established science issues linked to perceived knowledge and deference to science'. International Journal of Public Opinion Research. https://doi .org/10.1093/ijpor/edaa010.

Akin, H., Rose, K. M., Scheufele, D. A., Simis-Wilkinson, M., Brossard, D., Xenos, M. A. and Corley, E. A. (2017). 'Mapping the landscape of public attitudes on synthetic biology'. BioScience 67 (3), pp. 290-300. https://doi.org/10.1093/biosci/biw171.

Anderson, C. B., Lee, H. Y., Byars-Winston, A., Baldwin, C. D., Cameron, C. and Chang, S. (2016). 'Assessment of scientific communication self-efficacy, interest, and outcome expectations for career development in academic medicine'. Journal of Career Assessment 24 (1), pp. 182-196. https://doi.org/10.1177/1069072714565780.

Bankston, A. and McDowell, G. S. (2018). 'Changing the culture of science communication training for junior scientists'. Journal of Microbiology $\mathcal{E}$ Biology Education 19 (1). https://doi.org/10.1128/jmbe.v19i1.1413.

Baram-Tsabari, A. and Osborne, J. (2015). 'Bridging science education and science communication research'. Journal of Research in Science Teaching 52 (2), pp. 135-144. https://doi.org/10.1002/tea.21202.

Besley, J. C., Dudo, A. and Storksdieck, M. (2015). 'Scientists' views about communication training'. Journal of Research in Science Teaching 52 (2), pp. 199-220. https://doi.org/10.1002/tea.21186. 
Besley, J. C., Dudo, A. and Yuan, S. (2018). 'Scientists' views about communication objectives'. Public Understanding of Science 27 (6), pp. 708-730. https://doi.org/10.1177/0963662517728478.

Besley, J. C. and Nisbet, M. (2013). 'How scientists view the public, the media and the political process'. Public Understanding of Science 22 (6), pp. 644-659. https://doi.org/10.1177/0963662511418743.

Besley, J. C., O'Hara, K. and Dudo, A. (2019). 'Strategic science communication as planned behavior: understanding scientists' willingness to choose specific tactics'. PLoS ONE 14 (10), e0224039. https://doi.org/10.1371/journal. pone.0224039.

Besley, J. C. and Tanner, A. H. (2011). 'What science communication scholars think about training scientists to communicate'. Science Communication 33 (2), pp. 239-263. https://doi.org/10.1177/1075547010386972.

Byrnes, J. E. K., Ranganathan, J., Walker, B. L. E. and Faulkes, Z. (2014). 'To crowdfund research, scientists must build an audience for their work'. PloS ONE 9 (12), e110329. https://doi .org/10.1371/journal . pone. 0110329.

Cirino, L. A., Emberts, Z., Joseph, P. N., Allen, P. E., Lopatto, D. and Miller, C. W. (2017). 'Broadening the voice of science: promoting scientific communication in the undergraduate classroom'. Ecology and Evolution 7 (23), pp. 10124-10130. https://doi.org/10.1002/ece3.3501.

Clark, G., Russell, J., Enyeart, P., Gracia, B., Wessel, A., Jarmoskaite, I., Polioudakis, D., Stuart, Y., Gonzalez, T., MacKrell, A., Rodenbusch, S., Stovall, G. M., Beckham, J. T., Montgomery, M., Tasneem, T., Jones, J., Simmons, S. and Roux, S. (2016). 'Science educational outreach programs that benefit students and scientists'. PLoS Biology 14 (2), e1002368. https://doi.org/10.1371/journal.pbio.1002368.

Copple, J., Bennett, N., Dudo, A., Moon, W.-K., Newman, T. P., Besley, J., Leavey, N., Lindenfeld, L. and Volpe, C. (2020). 'Contribution of training to scientists' public engagement intentions: a test of indirect relationships using parallel multiple mediation'. Science Communication 42 (4), pp. 508-537. https://doi.org/10.1177/1075547020943594.

Dudo, A. (2013). 'Toward a model of scientists' public communication activity: the case of biomedical researchers'. Science Communication 35 (4), pp. 476-501. https://doi.org/10.1177/1075547012460845.

Dudo, A. and Besley, J. C. (2016). 'Scientists' prioritization of communication objectives for public engagement'. PLoS ONE 11 (2), e0148867. https://doi.org/10.1371/journal.pone.0148867.

Dunwoody, S. and Griffin, R. J. (2015). 'Risk information seeking and processing model'. In: The SAGE handbook of risk communication. Ed. by H. Cho, T. Reimer and K. A. McComas. Thousand Oaks, CA, U.S.A.: SAGE Publications.

Eagly, A. H. and Chaiken, S. (1993). The psychology of attitudes. Orlando, FL, U.S.A.: Harcourt Brace Jovanovich College Publishers.

Flynn, J., Slovic, P. and Mertz, C. K. (1994). 'Gender, race, and perception of environmental health risks'. Risk Analysis 14 (6), pp. 1101-1108. https://doi.org/10.1111/j.1539-6924.1994.tb00082.x.

Griffin, R. J., Dunwoody, S. and Yang, Z. J. (2013). 'Linking risk messages to information seeking and processing'. Annals of the International Communication Association 36 (1), pp. 323-362. https://doi.org/10.1080/23808985.2013.11679138.

Griffin, R. J., Yang, Z., ter Huurne, E., Boerner, F., Ortiz, S. and Dunwoody, S. (2008). 'After the flood: anger, attribution, and the seeking of information'. Science Communication 29 (3), pp. 285-315.

https://doi.org/10.1177/1075547007312309. 
Illman, D. L. (2010). 'Engaging students in science communication'. In: Science education and civic engagement: the SENCER approach. Ed. by R. D. Sheardy. Vol. 1037. ACS Symposium Series. American Chemical Society, pp. 135-147. https://doi.org/10.1021/bk-2010-1037.ch009.

Jeno, L. M. (2015). 'Encouraging active learning in higher education: a Self-Determination Theory perspective'. International Journal of Technology and Inclusive Education Special Issue 2 (1), pp. 694-699. https://doi.org/10.20533/ijtie.2047.0533.2015.0091.

Jeno, L. M., Danielsen, A. G. and Raaheim, A. (2018). 'A prospective investigation of students' academic achievement and dropout in higher education: a Self-Determination Theory approach'. Educational Psychology 38 (9), pp. 1163-1184. https://doi.org/10.1080/01443410.2018.1502412.

Jensen, P., Rouquier, J.-B., Kreimer, P. and Croissant, Y. (2008). 'Scientists who engage with society perform better academically'. Science and Public Policy 35 (7), pp. 527-541. https://doi .org/10.3152/030234208X329130.

Liang, X., Su, L. Y.-F., Yeo, S. K., Scheufele, D. A., Brossard, D., Xenos, M., Nealey, P. and Corley, E. A. (2014). 'Building buzz: (scientists) communicating science in new media environments'. Journalism \& Mass Communication Quarterly 91 (4), pp. 772-791. https://doi.org/10.1177/1077699014550092.

Lundborg, P. and Andersson, H. (2008). 'Gender, risk perceptions, and smoking behavior'. Journal of Health Economics 27 (5), pp. 1299-1311. https://doi.org/10.1016/j.jhealeco.2008.03.003.

Manstead, A. S. R. (2011). 'The benefits of a critical stance: a reflection on past papers on the theories of reasoned action and planned behaviour'. British Journal of Social Psychology 50 (3), pp. 366-373. https://doi.org/10.1111/j.2044-8309.2011.02043.x.

Matthews, K. E. and Mercer-Mapstone, L. D. (2018). 'Toward curriculum convergence for graduate learning outcomes: academic intentions and student experiences'. Studies in Higher Education 43 (4), pp. 644-659. https://doi.org/10.1080/03075079.2016.1190704.

McKinnon, M. and Vos, J. (2015). 'Engagement as a threshold concept for science education and science communication'. International Journal of Science Education, Part B 5 (4), pp. 297-318. https: //doi.org/10.1080/21548455.2014.986770.

Montaño, D. E. and Kasprzyk, D. (2015). 'Theory of reasoned action, theory of planned behavior, and the integrated behavioral model'. In: Health behavior: theory, research, and practice. Ed. by K. Glanz, B. K. Rimer and K. Viswanath. 5th ed. San Francisco, CA, U.S.A.: Jossey-Bass/Wiley, pp. 95-124.

National Academies of Sciences, Engineering, and Medicine (2017). Communicating science effectively: a research agenda. Washington, DC, U.S.A.: The National Academies Press. https://doi .org/10.17226/23674.

- (2018). Graduate STEM education for the 21st Century. Ed. by A. Leshner and L. Scherer. Washington, DC, U.S.A.: The National Academies Press. https://doi.org/10.17226/25038.

Neeley, L., Goldman, E., Smith, B., Baron, N. and Sunu, S. (2014). GradSciComm report and recommendations: mapping the pathways to integrate science communication training into STEM graduate education. COMPASS. URL: https: //www. informalscience.org/gradscicomm-report-and-recommen dations-mapping-pathways-integrate-science-communication-training.

O'Keeffe, K. and Bain, R. (2018). 'ComSciCon-triangle: regional science communication training for graduate students'. Journal of Microbiology $\mathcal{E}$ Biology Education 19 (1). https://doi.org/10.1128/jmbe.v19i1.1420. 
Poliakoff, E. and Webb, T. L. (2007). 'What factors predict scientists' intentions to participate in public engagement of science activities?' Science Communication 29 (2), pp. 242-263. https://doi.org/10.1177/1075547007308009.

Priest, S. (2013). 'Critical science literacy: what citizens and journalists need to know to make sense of science'. Bulletin of Science, Technology E Society 33 (5-6), pp. 138-145. https://doi.org/10.1177/0270467614529707.

Ritchie, T. S. and McCartney, M. (2019). 'Providing transferable, professional skills for the next generation of scientific professionals through an outreach opportunity'. Journal of STEM Outreach 2 (1). https://doi.org/10.15695/jstem/v2i1.15.

Rizzolo, S., DeForest, A. R., DeCino, D. A., Strear, M. and Landram, S. (2016). 'Graduate student perceptions and experiences of professional development activities'. Journal of Career Development 43 (3), pp. 195-210. https://doi.org/10.1177/0894845315587967.

Rodgers, S., Wang, Z., Maras, M. A., Burgoyne, S., Balakrishnan, B., Stemmle, J. and Schultz, J. C. (2018). ‘Decoding science: development and evaluation of a science communication training program using a triangulated framework'. Science Communication 40 (1), pp. 3-32. https://doi .org/10.1177/1075547017747285.

Rodgers, S., Wang, Z. and Schultz, J. C. (2020). 'A scale to measure science communication training effectiveness'. Science Communication 42 (1), pp. 90-111. https://doi.org/10.1177/1075547020903057.

Scheufele, D. A. (2014). 'Science communication as political communication'. Proceedings of the National Academy of Sciences 111 (Supplement 4), pp. 13585-13592. https://doi.org/10.1073/pnas.1317516111.

Schwarzer, R. and Jerusalem, M. (1995). 'Generalized self-efficacy scale'. In: Measures in health psychology: a user's portfolio. Causal and control beliefs. Ed. by J. Weinman, S. Wright and M. Johnston. Windsor, U.K.: NFER-Nelson, pp. 35-37.

Warren, D. R., Weiss, M. S., Wolfe, D. W., Friedlander, B. and Lewenstein, B. (2007). 'Lessons from science communication training'. Science 316 (5828), p. 1122. https://doi.org/10.1126/science.316.5828.1122b.

Dr. Heather Akin is an Assistant Professor of Strategic Communication in the Department of Agricultural Leadership, Education, and Communication at the University of Nebraska-Lincoln in the United States. E-mail: heather.akin@unl.edu.

Dr. Shelly Rodgers is a Professor of Strategic Communication in the Missouri School of Journalism at the University of Missouri in the United States. E-mail: srodgers@missouri.edu.

Dr. Jack C. Schultz is the Senior Executive Director for Research and Development at the University of Toledo in the United States. E-mail: john.schultz@utoledo.edu.

How to cite

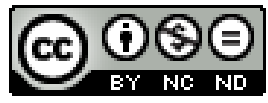

Akin, H., Rodgers, S. and Schultz, J. C. (2021). 'Science communication training as information seeking and processing: a theoretical approach to training early-career scientists'. JCOM 20 (05), A06. https:/ / doi.org/10.22323/2.20050206. 